\title{
A case report of acute pediatric bacterial meningitis due to the rare isolate, Pseudomonas putida
}

\author{
Grishma V. Kulkarni \\ Max Cure Hospitals (Mediciti Hospital), Hyderabad 500063, Andhra Pradesh, India.
}

Correspondence to: Dr. Grishma V. Kulkarni, Max Cure Hospitals (Mediciti hospital), \#5-9-22, Secretariat Road, Hyderabad 500063, Andhra Pradesh, India. E-mail: drgrishmak@gmail.com

How to cite this article: Kulkarni GV. A case report of acute pediatric bacterial meningitis due to the rare isolate, Pseudomonas putida. Neuroimmunol Neuroinflammation 2016;3:215-8.

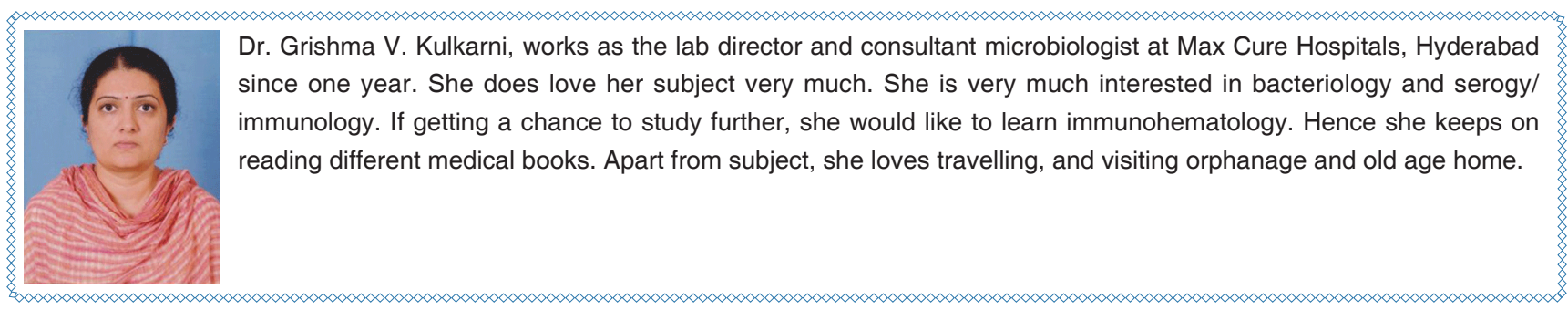

Article history:

Received: 13-12-2015

Accepted: 01-04-2016

Published: 26-09-2016

Key words:

Acute bacterial meningitis,

cerebrospinal fluid,

Pseudomonas putida

\section{ABSTRACT}

Acute bacterial meningitis (ABM) is the medical emergency which warrants an early diagnosis and an aggressive therapy. Despite the availability of the potent newer antibiotics, the mortality caused by ABM and its complications remain high in India, ranging from 16\% to $32 \%$. The aim of this case report is to present the rare isolation of Pseudomonas putida from cerebrospinal fluid sample. Besides this, the author also emphasizes the importance of correctly identifying the organism and thus the selection of the most accurate antibiotic from the susceptibility profile to allow for early recovery and to improve the patient outcome and survival.

\section{INTRODUCTION}

Bacterial meningitis can cause death if not treated early and aggressively both in the developed and developing countries. ${ }^{[1]}$ Untreated, the mortality approaches $100 \%$, and even with the current antibiotics and advanced pediatric intensive care, the mortality rate of disease is approximately $5 \%$ to $10 \% \cdot{ }^{[2]}$ Worldwide, the neurological 
aftereffects of the meningitis in the survivors following the hospital discharge approaches $20 \%{ }^{[2,3]}$ Risks of long-term disabling secondary results were highest in low-income countries, where the burden of bacterial meningitis is the greatest. Most of these reported results could have been averted by vaccination with Hib, pneumococcal, and meningococcal vaccines. ${ }^{[3]}$ Hence early diagnosis and appropriate management of children with meningitis is critical as it can be difficult to diagnose as the symptoms and signs are often nonspecific especially in young children. ${ }^{[2]}$

\section{CASE REPORT}

A 5-year-old girl, a known case of opsomyclonus syndrome and is therefore being treated for this autoimmune condition with steroids for the past 2 years, she was referred Lotus hospital on March 3th, 2015 , with the symptoms of fever, vomitings (7-8 episodes) and reduced appetite for the last $48 \mathrm{~h}$ and altered sensorium for the last $24 \mathrm{~h}$. She had the past history of ataxia. On assessment, the growth and the development were appropriate for her age. Her heart rate was $168 / \mathrm{min}$, respiratory rate was $61 / \mathrm{min}$, blood pressure (BP) was $77 / 38 \mathrm{mmHg}$. On physical examination, she had sunken eyes and wound over the knee. Her tongue appeared to be dry. Respiratory exam showed that she had tachypnea. Central nervous system examination showcased that she was drowsy and Glasgow coma score (GCS) was E3V3M4 and hypotonia was present in the lower limbs. Pupils were bilaterally equal and reacting to the light. On abdominal exam, abdomen was distended. In view of the poor GCS, she was intubated and mechanical ventilator support was continued. Her blood gases were monitored regularly.

Her complete blood picture was normocytic and normochromic. The cell counts and erythrocyte sedimentation rate were within normal limits except neutrpohils (neutrophilia) and platelets (thrombocytosis). Blood urea nitrogen, serum calcium, serum creatinine $(1.2 \mathrm{mg} / \mathrm{dL})$ and serum electrolytes were out of range. Her serum glutamic oxaloacetic transaminase was $152 \mathrm{IU} / \mathrm{L}$ and her test results for malarial antigen were negative. Her blood ammonia was within normal range. Complete urine examination showcased 10 pus cells/high power field whereas the culture results showed that she was sterile. Routine examination of her stool was negative. Blood cultures were negative for bacterial growth. Oxygen saturation was $55 \%$. Ultrasonography of the abdomen showed mild ascitis and her fundus examination was normal.

In view of the history and clinical features, she was diagnosed as meningitis with status epileptics with the lower respiratory tract infection. Cerebrospinal fluid (CSF) analysis showed a normal white blood cell count ( 0.4 cells/cumm and lymphocytes 100\%), normal proteins $(26.6 \mathrm{mg} / \mathrm{dL})$ and elevated sugar levels $(112.7 \mathrm{mg} / \mathrm{dL})$.

Gram stain did not show any organism and pus cells. However, CSF culture grew Gram-negative organism which on further biochemical evaluation was identical to Alcaligenes fecalis. The organism was later on identified as Pseudomonas putida with automated identification system, VITEK ${ }^{\circledR} 2$ (BIOMERIEUX, USA).

The patient was treated initially with injection of piperacillin with tazobactum, vancomycin, meropenem, acyclovir and maintenance IV fluids. In addition to this, she received injection phenytoin followed by phenobarbitone and anticerebral edema measures; computed tomography scan of the brain was normal. As per the clinical findings, a possibility of severe sepsis with septic shock was considered. Her 2D $\mathrm{ECHO}$ was done and showed normal heart with mild, bilateral pleural effusion, inferior vena cava was noncollapsed and dilated. Her fluid bolus was optimized and she was commenced on the vasoactive agents in view of refractory shock. C-reactive protein was elevated (46 mg/L).

Pseudomonas putida displayed in vitro sensitivity to amikacin, ciprofloxacin, levofloxacin and minocycline and moderately sensitivity to gentamicin and cefepime. It was totally resistant to piperacillin and tazobactum, cefoperazone and sulbactum, cotrimoxazole, doripenem and tigeycycline. Hence the antibiotics were change to amikacin. Gradually her hemodynamics improved with the reversal of shock state.

Her chest X-ray showed the right lower lobe consolidation. She was extubated after 6 days and received chest physiotherapy. On the day of discharge, March 26th, 2015, her BP was $110 / 54 \mathrm{mmHg}$, and oxygen saturation was $98 \%$ and all organ systems examinations were normal.

\section{DISCUSSION}

Acute bacterial meningitis (ABM) is the dangerous disease if found in young children and has a high rate of fatality and risk of neurological handicaps. ${ }^{[4]}$ In the developed countries, N.meningitidis and S.pneumoniae are the most prevalent cause of the acute bacterial meningitis ${ }^{[2]}$ whereas H.influenzae, N.meningitidis and S.pneumoniae are responsible for ABM in the developing countries. ${ }^{[4,5]}$ 
In a Spanish prospective observational study, $69.4 \%$ and $30.5 \%$ cases of meningitis are community and nosocomially acquired respectively. ${ }^{[6]}$ The etiologic agents of community acquired meningitis are H.influenzae, N.meningitidis and S.pneumoniae whereas nosocomial meningitis is caused by Gramnegative bacilli (GNB) and Staphylococcus sp. ${ }^{[6]}$ Another Spanish neonatal meningitis study revealed $55.6 \%$ and $44.37 \%$ of meningitis cases were vertically and nosocomially transmitted respectively. S.agalactiae was reported in $48.5 \%$ confirmed cases of meningitis and in other cases E.coli and S.epidermidis were isolated from $26.5 \%$ and $24.5 \%$ of the cases respectively. ${ }^{[7]}$

In an 8-year study from the Northern region of India, the majority of the patients $(83.8 \%)$ were younger than 12 years and majority of them were infants $(36.7 \%)$. Majority of the meningitis cases $(69.2 \%)$ were community acquired and $30.8 \%$ were hospital acquired. Overall, S.aureus predominated during the 8 years study period accounting for the total of $38 \%$ of all isolates followed by Pseudomonas sp (12\%) and E.coli $(11 \%){ }^{[8]}$

In the present study, Pseudomonas putida was isolated from a 5 -year-old girl. Bareja et al. ${ }^{[9]}$ in a study on the trends in bacteriology of meningitis reported, P.aeruginosa to be responsible for $9.23 \%$ of pediatric meningitis cases, out of which majority of them $(29.4 \%)$ were seen in 1 to 3 years old children, less frequently were observed between 3 to 12 months of age group children (17.64\%) and in 3 to 5 years old children (17.64\%). Archibald et al. ${ }^{[10]}$ reported 2 cases of Pseudomonas aeruginosa childhood meningitis. Yang et al. ${ }^{[11]}$ isolated P.putida in CSF causing meningitis in 2 of their 55 patients $(5 \%)$ with P.putida infections.

In the present study, Gram stain did not show any organism and pus cells. In addition to this, blood and urine culture were sterile. CSF culture grew GNB resembling Alcaligenes fecalis (identified with limited number of conventional biochemical tests) and later on identified as Pseudomonas putida with automated VITEK $^{\circledR} 2$ (BIOMERIEUX, USA) system. Modi et al. ${ }^{[12]}$ in a study on 252 CSF samples in patients with acute childhood bacterial meningitis; 162 (64.3\%) were smear positive and $200(79.4 \%)$ were and culture positive. Bareja et al. ${ }^{[9]}$ reported only $58 \%$ Gram stain positive samples and $23.5 \%$ culture positive. Almost similar results of positive Gram stain $(67 \%)$ and cultures $(50 \%)$ were reported by Chinchankar et al. ${ }^{[4]}$

In the present study, CSF analysis showed normal cell count, normal protein and elevated sugar. Bareja et al. ${ }^{[9]}$ found increase in the cell count in more than $90 \%$ of their culture positive specimen. On the contrary, Modi et al. ${ }^{[12]}$ reported the cell count of CSF sample to vary from no cells to sheets of cells; they also reported high mean level of protein $(90.2 \pm 11.5 \mathrm{mg} / \mathrm{dL})$ and a mean sugar level of $32.2 \pm 3.4 \mathrm{mg} / \mathrm{dL}$.

We did not perform CSF C-reactive protein, latex agglutination test (LAT) and polymerase chain reaction (PCR). Chinchankar et al. ${ }^{[4]}$ reported CSF C-reactive protein and LAT positive in $41 \%$ and $78 \%$ of the cases respectively while culture was positive in only $50 \%$ of the cases. Finlay et al. ${ }^{[13]}$ in their study, LAT confirmed the etiology of meningitis in $60 \%$ cases of S.pneumoniae, $93 \%$ of $H$.influenzae type B and $39 \%$ of N.meningitidis. It also explains that though Gram stain and LAT were positive in $50 \%$ of the cases after receiving the antibiotics, LAT is beneficial to identify the causative agent and to start the early treatment and vaccination of the patient, specially in case of meningococcal types A and C. On the contrary, low sensitivity of LAT (13.5\%) was reported by Tarafdar et al. ${ }^{[14]}$ in a brief report on culture negative meningitis.

Broad range PCR for the early detection of bacterial meningitis showed $100 \%$ sensitivity, $98.2 \%$ specificity, $94 \%$ positive predictive value and $100 \%$ negative predictive value. ${ }^{[15]}$ Similarly, the other analytical study displayed $54.5 \%$ sensitivity of the multiplex PCR in comparison with Gram stain $(29.2 \%)$ and culture $(34.5 \%) \cdot{ }^{[16]}$

Intially, in this case patient was treated with piperacillin and tazobactum, meropenem and vancomycin. Pseudomonas putida displayed in vitro sensitivity to amikacin, ciprofloxacin, levofloxacin and minocycline and moderate sensitivity to gentamicin and cefepime. It was totally resistant to piperacillin and tazobactum, cefoperazone and sulbactum, cotrimoxazole, doripenem and tigeycycline. Later on the antibiotics were upgraded and patient gradually recovered. Results of the in vitro susceptibility test suggested that imipenem and ceftazidime were more effective than the other antimicrobials against $P$.putida. ${ }^{[11]}$ Similarly, as per other CSF antibiogram analysis all strains of Pseudomonas $\mathrm{sp}$ were sensitive to imipenem. ${ }^{[12]}$

In conclusion, ABM is the medical emergency with high mortality rates. Rapid diagnosis and treatment are critical. We report a rare case of $P$. putida meningitis which was successfully treated. An infection with rare organisms is possible and a high index of suspicion can lead to accurate diagnosis and treatment in these cases.

Traditional lab methods such as Gram stain and culture are used for identification of organism. PCR is the rapid, 
accurate, sensitive and specific method for diagnosis of meningitis as this assay detects 10 to $100 \mathrm{CFU} / \mathrm{mL}$ of bacteria in CSF. ${ }^{[16]}$

\section{Financial support and sponsorship}

Nil.

\section{Conflicts of interest}

There are no conflicts of interest.

\section{Patient consent \\ Obtained.}

\section{Ethics approval}

The patient was treated within the standards of Lotus Hospitals (where the work was done) and the report was approved.

\section{REFERENCES}

1. El Bashir H, Laundy M, Booy R. Diagnosis and treatment of bacterial meningitis. Arch Dis Child 2003;88:615-20.

2. Tacon CL, Flower O. Diagnosis and management of bacterial meningitis in the pediatric population: a review. Emerg Med Int 2012;2012:320309.

3. Edmond K, Clark A, Korczak VS, Sanderson C, Griffiths UK, Rudan I. Global and regional risk of disabling sequelae from bacterial meningitis: a systemic review and meta-analysis. Lancet Infect Dis 2010;10:317-28.

4. Chinchankar N, Mane M, Bhave S, Bapat S, Bavdekar A, Pandit A, Niphadkar KB, Dutta A, Leboulleux D. Diagnosis and outcome of acute bacterial meningitis. Indian Pediatr 2002;39:914-21.
5. Kumar P, Verma IC. Antibiotic therapy for bacterial meningitis in children in developing countries. Bull World Health Organ 1993;71:183-8.

6. Elvira J, García del Río E, Chamorro J, López Suárez A, Tinoco I Rodríguez Leal MC, Vara F, García Tapia A, Girón González JA. A prospective study of meningitis diagnosed in a 3rd level hospital during a 1 yrperiod. Rev Clin Esp 1999;199:576-82.

7. Grupo de Hospitales Castrillo. Neonatal meningitis. Epidemiology study of the Grupo de Hospitales Castrillo. An Esp Pediatr 2002;56:556-63.

8. Khan F, Rizvi M, Fatima N, Shukla I, Malik A, Khatoon R. Bacteria meningitis in north india: trends over period of eight years. Neurology Asia 2011;16:47-56.

9. Bareja R, Pottahil S, Shah RK, Grover P, Singh VA. Trends in bacterial etiology amongst cases of meningitis. $J$ Acad Indus Res 2013;1:761-5.

10. Hoyne AL, Metrick S, Sakuma T. Pseudomonas aeruginosa infections: reports of two patients with meningitis. J Padiatr 1958;56:708-11.

11. Yang CH, Young T, Peng MY, Weng MC. Clinical spectrum of Pseudomonas putida infection. J Formos Med Assoc 1996;95:754-61.

12. Modi S, Anand AK. Phenotypic characterization and antibiogram of CSF isolates in acute bacterial meningitis. J Clin Diagn Res 2013;7:2704-8.

13. Finlay FO, Witherow $\mathrm{H}$, Rudd PT. Latex agglutination testing in bacterial meningitis. Arch Dis Child 1995;73:160-1.

14. Tarafdar K, Rao S, Recco RA, Zaman MM. Lack of sensitivity of Latex agglutination test to detect bacterial antigen in CSF of patients with Culture-negative meningitis. Clin Infect Dis 2001;33:406-8.

15. Saravolatz LD, Manzor O, Vander Velde N, Pawlak J, Belian B. Broadrange bacterial PCR early detection of bacterial meningitis. Clin Infect Dis 2003;36:40-5

16. Yahia MA, Balach O. Comparison of multiplex PCR, Gram stain and culture for diagnosis of acute bacterial meningitis. Int J Pharm Pharm Sci 2014;6:425-9. 